\title{
Combined Effects of Long-Term Sitting and Whole-Body Vibration on Discomfort Onset for Vehicle Occupants
}

\author{
Neil J. Mansfield, Jamie Mackrill, Andrew N. Rimell, and Simon J. MacMull \\ Loughborough Design School, Loughborough University, Loughborough LE11 3TU, UK \\ Correspondence should be addressed to Neil J. Mansfield; n.j.mansfield@lboro.ac.uk
}

Received 11 June 2013; Accepted 22 July 2013; Published 2 January 2014

Academic Editors: A. Anund and M. Gobbi

Copyright (C) 2014 Neil J. Mansfield et al. This is an open access article distributed under the Creative Commons Attribution License, which permits unrestricted use, distribution, and reproduction in any medium, provided the original work is properly cited.

Occupants of automobiles experience discomfort after long drives, irrespective of how well designed a seat might be. Previous studies of discomfort during driving have focused either on the seat shape and materials ("static" properties), long-term discomfort ("fatigue" properties), or dynamics ("vibration" properties). These factors have previously not been considered together. This paper reports three studies with objectives to define and test a model for describing long-term discomfort from vibration. Study 1 was an independent measures laboratory trial using an automobile seat, which lasted 80 minutes; Study 2 was a repeated measures laboratory trial using a rail passenger seat, which lasted 60 minutes; Study 3 was a repeated measures field trial in a people carrier automobile, which involved 70 minutes of travelling. The findings showed that discomfort accrues with time but that more discomfort is experienced when subjects are also exposed to whole-body vibration. Exposure to whole-body vibration accelerates development of discomfort. The relationship between the reported discomfort, the vibration magnitude, and the exposure time can be described using a multifactorial linear model. It is concluded that ignoring parts of the multi-factorial model (i.e., static, dynamic, or temporal factors) will compromise understanding of discomfort in context.

\section{Introduction}

Long-term exposure to vibration whilst driving or travelling as a passenger in an automobile has been associated with discomfort, increased prevalence of low back pain, and other musculoskeletal disorders (e.g. [1-7]). Subjective reports of discomfort are often considered as precursors of injury, and much experimental work on physical effects of whole-body vibration has used subjective ratings of discomfort as the experimental method. Factors affecting the discomfort could include the physical shape of the seat, the fit of the seat to the occupant, the materials which the seat is made from (which will dictate its stiffness), the thermal environment to which the occupant is exposed, exposure to wholebody vibration and/or mechanical shocks, opportunity for changing postures (thus changing the muscle groups which are supporting the body weight), and the length of time the occupant has been sitting in the seat (e.g. $[8,9])$.

Ebe and Griffin $[3,4]$ proposed a qualitative and quantitative model of overall seat discomfort. The approach of their model was to separate discomfort into "static" seat factors and "dynamic" seat factors. Static factors focused on seat stiffness, but these could also include any factor which does not change in response to the dynamic environment of the vehicle. Dynamic factors are those which are related to the whole-body vibration caused by the vehicle environment. The concept of Ebe's model is that, when vibration is absent, the total seat discomfort is dictated by the static factors, but if there is a vibration input to the seat, the total seat discomfort comprises a combination of static factors and dynamic factors. Thus, as the vibration magnitude increases, the relative importance of the dynamic increases accordingly.

For some vehicle environments, the typical magnitude of the vibration entering the seat is low. This could be due to smooth road surfaces and high quality vehicle suspension [10]. In this case, the dynamic seat factors are less important than the static seat factors and therefore improved comfort could be achieved by optimising the static factors (such as seat stiffness, fit/adjustments, and seat shape). However, should the seat be exposed to high vibration magnitudes, it might not 
perform very well, resulting in a poor "ride" for the occupant. An example of this type of case is a luxury car which is driven on relatively smooth surfaces (asphalt roads) and has a high specification suspension. Other vehicle environments expose the seat to high magnitudes of vibration. This could be due to a requirement to drive off-road or on rough roads. In this case, the dynamic seat factors can be as (or more) important as the static seat factors and therefore improved comfort would require optimisation of both static and the dynamic seat factors. However, when the vehicle is driving on smooth surfaces, the static properties of the seat might not be optimal.

It is well known that sitting in the same posture for extended periods of time will lead to discomfort. It is recommended that sitting comfort trials for car seats have a duration of at least 2 hours to differentiate between seat designs [2]. At the beginning of a sitting trial, Porter et al. [11] showed that although some seats are considered uncomfortable by about $1 / 3$ of participants after 15 minutes, others are initially considered comfortable but become uncomfortable after about one hour. Postural changes can affect the biomechanical response of the body (e.g., [12-14]). Similarly the position of the arms can affect biomechanics (e.g., [15]) either providing an addition vibration input, if the arms are holding a steering wheel, or acting as a vibration absorber.

If seat discomfort is assessed under "showroom" conditions, evaluations are short and do not involve exposure to whole-body vibration. Both of these factors have been shown to be important by previous researchers. Porter et al. have shown that short-term evaluations whilst driving are likely to be inadequate, as they fail to consider the effects of fatigue and long-term sitting; Ebe and Griffin have shown that evaluations which do not include vibration are likely to be inadequate, as they fail to consider the effects of wholebody vibration exposure. Previous studies have shown the effects of long-term sitting or the effects of vibration, but few studies combine both factors. Studies of the effect of vibration duration have focused on short exposures unrepresentative of work environments (e.g., [16]) or have focused on changes in relative sensitivity to different frequencies of vibration over time, rather than the overall discomfort (e.g., [17]). A multifactorial conceptual model to predict overall discomfort has previously been suggested ([18] Figure 1) but there have as yet been limited validation and verification. The model combines static factors, dynamic factors, and temporal factors which combine to provide an overall indication of overall discomfort. This paper reports results from two laboratory trials and one field trial with objectives of testing the model, refining the model, and numerically fitting the model to real data.

\section{Methodology}

Two laboratory trials and one field trial were completed to study the relative contribution from static, dynamic, and temporal factors of discomfort for different vehicle seats and experimental contexts. Each study used vibration exposure and sitting time as independent variables and measures of discomfort using Porter's 7-point comfort rating scale (Figure 2) each 10 minutes as the dependent variable [11]. Subjects were asked to "rate body part comfort/discomfort according to the

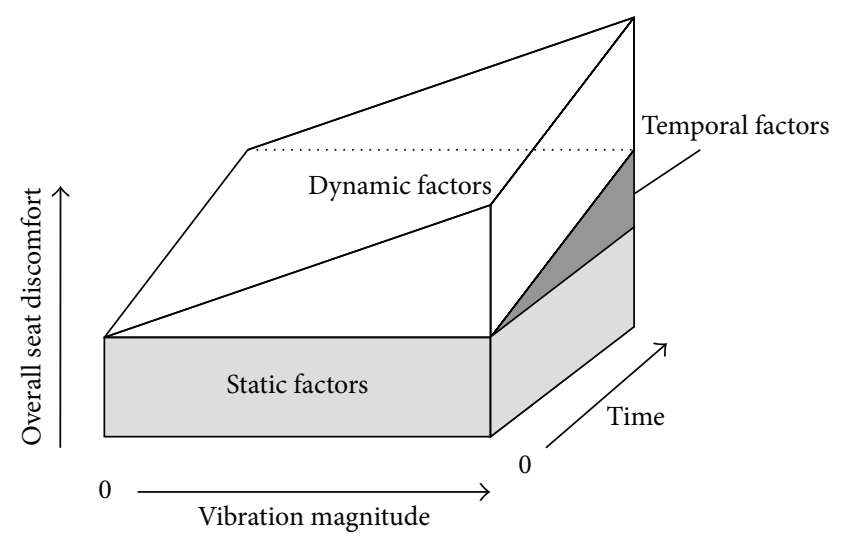

Figure 1: A model of vehicle seat discomfort including static, dynamic, and temporal factors (from [18, page 33]).

7-point scale for each body part on the map"; no specific reference was made to "vibration discomfort", as this would not have been valid for the control conditions. For each body part, subjects gave a verbal response of the number relating to their comfort at each sample time after being prompted by the experimenter. These responses give an overall map of where discomfort is concentrated and this can be used to inform seat design and development. For this study, the key metric was the overall discomfort score. The overall discomfort score at each 10-minute sample was taken as the mean discomfort score reported across all body parts. Porter's scale was used as it is widely used in studies of automobile comfort and validated as such. Subjects were drawn from the staff and students of Loughborough University and included males and females in each study (Table 1). Although males and females were used in all studies, due to small sample sizes for subgroups, the studies lack sufficient statistical power to perform analyses of gender effects; therefore effects of gender are not considered here. Experimental design, seats and vibration exposures differed between the three studies and are detailed later. Different subjects were used in each study. Subjects were not given any specific task to complete during the trials and were able to see a large printout of the discomfort scale at all times. Thus there were no distractions from the comfort/discomfort experienced. The studies were approved by Loughborough University Ethical Advisory Committee. Two-way between subjects analysis of variance was used for comparisons between groups in Study 1; two-way within subject analysis of variance was used for Studies 2 and 3 and for comparison of the effects of time within condition in Study 1. Statistical analysis was carried out using SPSS v16.

\subsection{Study 1-Laboratory Study of Long-Term Discomfort in} an Automobile Seat. Study 1 used an independent measures design, using 36 volunteers randomly split into three groups of 12 subjects. 12 subjects were allocated to group "V0," who were not exposed to vibration; 12 were allocated to group "V1," who were exposed to a "low" magnitude of vibration; 12 were allocated to group "V2," who were exposed to a "high" magnitude of vibration. Subjects were required to sit in 


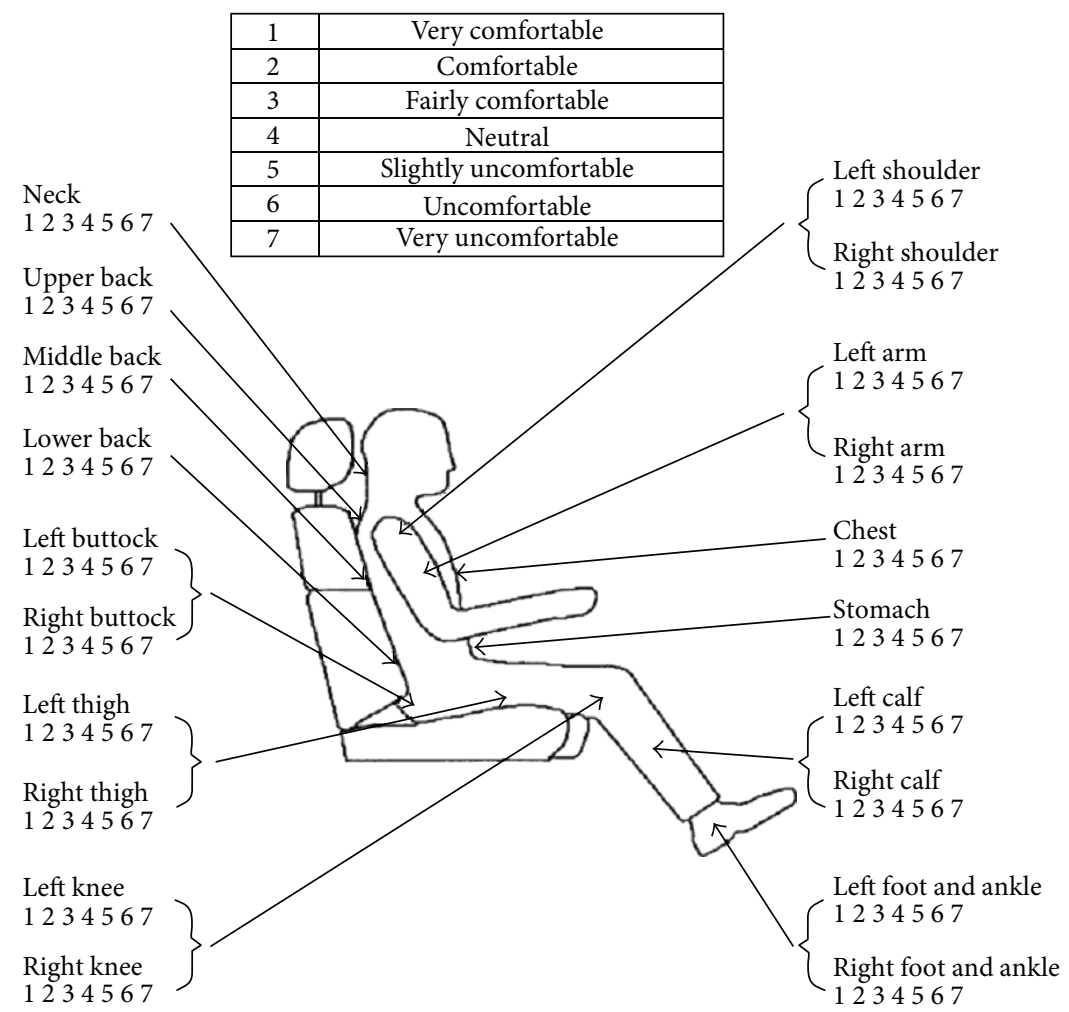

FIgURE 2: Porter's seven-point comfort rating scale, as used in the experiment [2].

TABle 1: Subject demographic data for the three studies. Data are given as means.

\begin{tabular}{lccccc}
\hline & Males & Females & Age (y) & $\begin{array}{c}\text { Height } \\
(\mathrm{cm})\end{array}$ & $\begin{array}{c}\text { Weight } \\
(\mathrm{kg})\end{array}$ \\
\hline Study 1 (V0) & $n=6$ & $n=6$ & 22.7 & 177 & 84 \\
Study 1 (V1) & $n=9$ & $n=3$ & 25.8 & 178 & 85 \\
Study 1 (V2) & $n=8$ & $n=4$ & 25.2 & 176 & 76 \\
Study 2 & $n=6$ & $n=6$ & 20.8 & 176 & 71 \\
Study 3 & $n=8$ & $n=8$ & 27.9 & 173 & 69 \\
\hline
\end{tabular}

a seat from a medium sized European car which was mounted on a 6-degree-of-freedom vibration simulator. Subjects were able to adjust the seat at the start of the experiment to a comfortable position. A footrest, mounted on the floor, was adjusted such that the knee angle was 120 degrees. Subjects held their hands in their laps. The back was in contact with the backrest.

An incoherent triaxial random translational vibration stimulus was used for those exposed to vibration (Gaussian, $1-20 \mathrm{~Hz}$ ). This was equalised to have a flat response at the base of the seat, although the dynamics of the seat modified the spectrum on the seat surface. Seat dynamics can be slightly different for different subjects, due to differential driving point mechanical impedance. Therefore the subject-seatshaker system was checked prior to each trial to equalise for this effect. This system characterisation procedure measured the vibration magnitude on the surface of the seat which was adjusted to the desired levels, measured using accelerometers mounted in a standard seat pad (PCB356) and a Larson Davis HVM100 human vibration meter. The vibration meter provided a real-time readout of vibration magnitude and allowed for the fine tuning of the vibration magnitude in all three axes to within $5 \%$ of the desired magnitudes. Once the desired magnitudes were achieved, the seat pad was removed such that it would not influence the reported discomfort. System characterisation also served as subject familiarisation with the laboratory. During the main experiment, the vibration at the base of the seat was monitored in real time; assuming that the transmissibility of the seat did not change (as verified during pilot trials), the vibration on the seat surface would therefore have remained constant at the required magnitude. Subjects in group V1 were exposed to 80 minutes of vibration with an unweighted magnitude of $0.3 \mathrm{~m} / \mathrm{s}^{2}$ r.m.s. in each axis $\left(\sim 0.5 \mathrm{~m} / \mathrm{s}^{2}\right.$ root sum of squares (r.s.s.)); subjects in group V2 were exposed to 80 minutes of vibration with a magnitude of $0.6 \mathrm{~m} / \mathrm{s}^{2}$ r.m.s. in each axis $\left(\sim 1.0 \mathrm{~m} / \mathrm{s}^{2}\right.$ r.s.s. $)$. Frequency weighted magnitudes were $0.17,0.16$, and $0.29 \mathrm{~m} / \mathrm{s}^{2}$ r.m.s. for $\mathrm{V} 1$ and $0.34,0.33$, and $0.58 \mathrm{~m} / \mathrm{s}^{2}$ r.m.s. for $\mathrm{V} 2$ in the $x$-, $y$-, and $z$-axes, respectively. Vibration magnitudes were representative of those that would be measured in "good" and "poor" road transportation. Subjects' vision was not manipulated as they needed to see the body part discomfort map.

At the start of the trial, subjects rated the static discomfort in the seat (i.e., no vibration). The vibration was then started, and within the first minute, those in the vibration groups (V1 and V2) were required to report their discomfort 
ratings according to Porter's scale. Subjects then rated their discomfort every 10 minutes. After the 80th minute's ratings, the vibration was stopped and subjects remained in the seat for a final set of ratings at 90 minutes, after which they were able to dismount from the simulator. As far as possible, conditions were identical for each of the groups: V0 cohort sat on the seat on the shaker whilst powered and raised to the neutral position, and thus the background noise in the laboratory was similar for all.

\subsection{Study 2-Laboratory Study of Long-Term Discomfort in a} Rail Seat. Study 2 used a repeated measures design with one group of 12 subjects each tested three times. The experimental procedure was similar to that for Study 1 except that subjects attended the laboratory on three different days and the order of presentation of vibration stimuli was randomised. Attendance at the laboratory was at the same time each day. Subjects sat in a standard-class rail passengers' seat for 60 minutes with 50 minutes of vibration (V1 and V2, as per study 1). Although the seat was designed to accommodate two passengers, only one participant occupied the seat at any time.

2.3. Study 3-Field Study of Long-Term Discomfort of Passengers in an Automobile. Study 3 used a repeated measures design with one group of 16 subjects. Subjects were each required to travel on a 70-minute journey in a people carrier automobile (a 2006 UK registered Renault Espace) and a simulation of the same journey but with no vibration. Presentation of stimuli was randomised. Four subjects were tested at a time with two seated in the middle and two in the rear row of the vehicle. In this study, ratings of discomfort were completed on a paper copy of the body map such that subjects would not influence each other's results.

Due to the nature of the road trials, vibration stimuli could not be set precisely. The predetermined test route was driven in the same direction and at a constant speed as to provide as much continuity to the vibration exposure between different groups as possible. The route included UK "A" and "B" roads and did not include motorways and was designed to provide a constant vibration, without major changes in road roughness. "A" roads represent single/dual carriageway trunk routes between towns; "B" roads represent local roads with lower traffic density than the "A" roads. The vibration measurements were conducted in accordance with ISO 2631-1 [19]. A triaxial accelerometer was mounted in a flexible disc and fixed in place beneath the ischial tuberosities of the driver who did not participate in the study. Vibration was not measured on each individual seat due to the need to ensure that discomfort ratings were not affected by the presence of the accelerometer mount. The accelerometer measured vibration in the 3 translational axes: fore and aft ( $x$ axis), lateral ( $y$-axis), and vertical ( $z$-axis). The acceleration was sampled at $500 \mathrm{~Hz}$ using a Biometrics DataLogger via antialiasing filters and downloaded to a PC for postanalysis using software developed in LabVIEW and compliant with ISO 8041. During the analysis process, the raw acceleration signals were frequency-weighted according to ISO 26311. Weighting $W_{k}$ was used in the vertical direction and weighting $W_{d}$ was used in the horizontal direction. Vibration magnitudes were $0.15,0.16$, and $0.25 \mathrm{~m} / \mathrm{s}^{2}$ r.m.s. in the $x-, y$-, and $z$-axis, respectively. These vibration magnitudes could have varied from position to position in the vehicle and therefore this is a limitation of the current study.

For the zero-vibration condition, subjects sat in the same automobile whilst parked in a darkened laboratory. A projection of the journey was displayed on a screen mounted in front of the car. The video also had sound which was played back through a set of speakers thus providing audio cue to the driving scenario.

\section{Results}

3.1. Study 1-Laboratory Study of Long-Term Discomfort in an Automobile Seat. For Study 1, subjects in group V0 were exposed to no vibration but were required to sit in the automobile seat for 90 minutes. This paralleled the experiments previously reported by Porter et al. Each of the 12 subjects in this group showed a general trend of increasing in discomfort as time accrued. Mean data from all subjects showed a monotonic relationship between overall discomfort and sitting time. These results are similar to those obtained in previous studies. Static discomfort in the seat before the start of the vibration had a mean of 1.3 for group V1 and 1.9 for group V2.

Study 1 used an independent measures design, where each subject experienced either V0, V1, or V2. Therefore, it is not possible to compare the responses of an individual subject for different vibration magnitudes. However, it is possible to compare cohort trends across the 80 minutes of the vibration exposure. At $T=0$ and $T=10$ mins, the mean discomfort was slightly lower for cohort V1 than V0 (Figure 3). The within-groups data for cohorts V1 and V2 showed a slight increase in mean discomfort between measurements taken with no vibration and the data from $T=0$. For all other combinations of time and vibration magnitude, there was a trend for discomfort to increase with vibration magnitude and with sitting duration. There was a significant main effect of time $\left(F_{(8,297)}=19.04, P<0.0005\right.$; between subjects ANOVA $)$ and vibration magnitude $\left(F_{(2,297)}=29.59, P<\right.$ 0.0005). There was no significant interaction between time and vibration magnitude $\left(F_{(16,297)}=0.955, P=0.506\right)$. Post hoc Tukey tests showed significant differences with time after 30 minutes $(P<0.001)$ and significant differences between each combination of vibration magnitude $(P<0.0005)$.

At 80 minutes, the vibration was stopped and subjects sat in the seat for a final 10 minutes at which point they gave their final discomfort rating. For conditions V1 and V2, the ratings of discomfort improved by about 0.5 points on the overall discomfort scale (Figure 3). Changes in discomfort rating over this time were significant (paired samples $t$-test, $P<0.01, \mathrm{~V} 1 ; P<0.05, \mathrm{~V} 2)$.

3.2. Study 2-Laboratory Study of Long-Term Discomfort in a Rail Seat. Study 2 comprised a repeated measures design and therefore it is possible to directly compare results across time and vibration magnitude. As for Study 1, each individual subject's discomfort increased with duration of sitting for each vibration condition (Figure 3). Similarly discomfort 

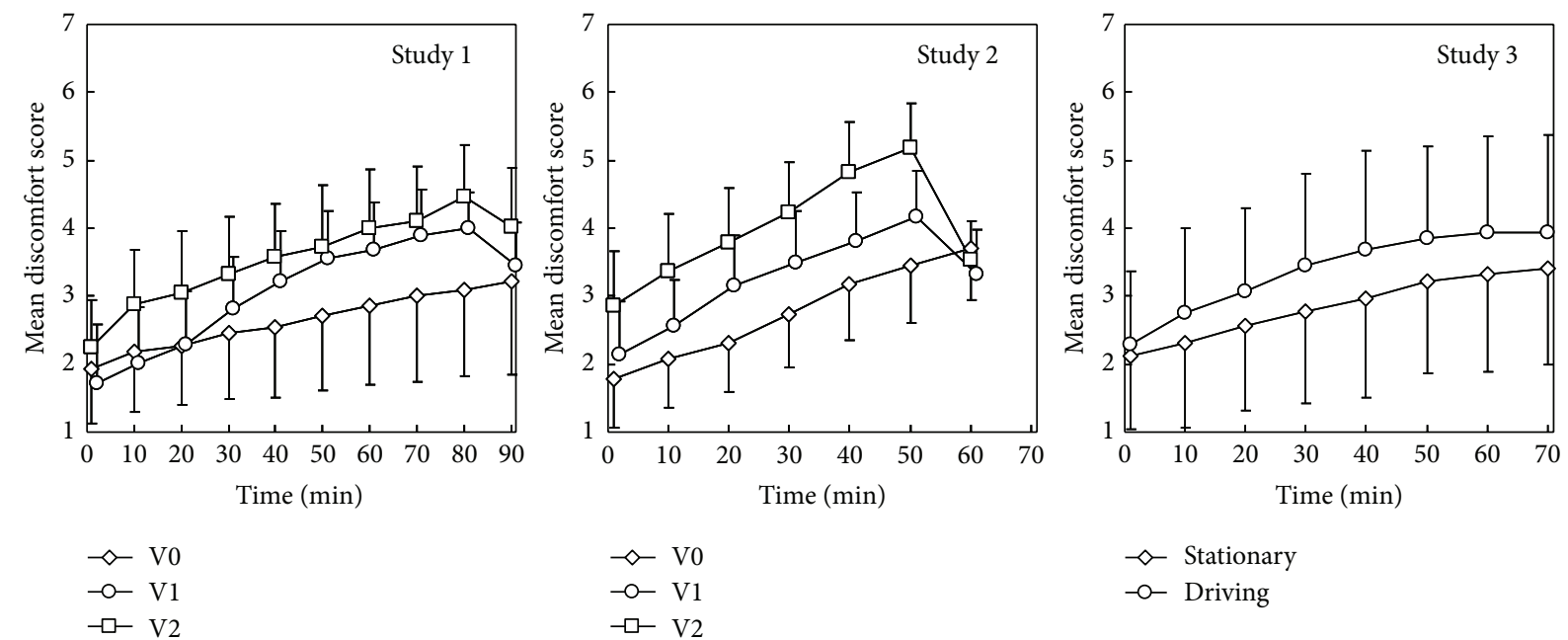

FIGURE 3: Mean discomfort scores for the 3 studies (jitter added on time axis to improve clarity; all data were obtained at 10-minute intervals). Error bars show standard deviation.

scores increased for each subject with increased vibration. There were significant main effects of time $\left(F_{(5,55)}=141.11, P<\right.$ $0.0005)$ and vibration magnitude $\left(F_{(2,22)}=37.42, P<0.0005\right)$. Interaction between time and vibration magnitude had a $P$ value of $0.065\left(F_{(11,110)}=1.82\right)$.

After 50 minutes, the vibration was stopped and subjects sat in the seat for a final 10 minutes at which point they gave their final discomfort rating. For conditions V1 and V2, the ratings of discomfort improved by about 1 point on the overall discomfort scale. At 50 minutes, differences between each of the three data sets were significant (paired samples $t$-test, $P<$ 0.005). After 10 minutes of stationary sitting postvibration exposure, all discomfort scores converged to a mean value of about 3.5 and there were no significant differences between them.

3.3. Study 3-Field Study of Long-Term Discomfort of Passengers in an Automobile. Study 3 used a repeated measures design. In both the stationary and the driving conditions, discomfort increased with time. Discomfort was slightly greater for the driving condition than for the stationary condition. Significant main effects occurred for time $\left(F_{(7,105)}=17.49\right.$, $P<0.0005)$; for driving condition the $P$ value was 0.097 $\left(F_{(1,15)}=3.127\right)$. There was no significant interaction between time and driving condition $\left(F_{(7,105)}=1.508, P=0.172\right)$.

\section{Discussion and Modelling}

For each of the sets of study results, mean discomfort increased with duration and increased with vibration magnitude. The effect of long-term sitting is in agreement with findings of Gyi and Porter [2], and the effect of vibration magnitude is in agreement with Ebe and Griffin [3, 4]. Combining the independent variables validates the previously suggested conceptual model [18]. Although it is apparent that increases in vibration and increases in sitting duration result in more discomfort, the presence of vibration accelerates the development of discomfort. At $t=0$, the mean differences between the control (zero vibration) and highest vibration for each study were 0.3 (Study 1), 1.1 (Study 2), and 0.2 (Study 3); these differences increased to $1.4,1.7$, and 0.5 , respectively, at the end of the vibration exposure.

Results show that any model designed to represent longterm overall discomfort when exposed to vibration needs to include factors able to represent the static discomfort (a constant for the seat), fatigue discomfort (a component which depends on time), vibration discomfort (a component which depends on the vibration magnitude), and interaction (a component of interaction between the vibration exposure and duration). The interaction component is used to represent the acceleration of development of discomfort during vibration exposure. Although interaction effects were not statistically significant in the two-way ANOVAs, these were required in the model which was fitted to mean data. These four variables can be expressed as

$$
\Psi=s_{s}+f_{t} t+d_{v} a+i_{t v} t a,
$$

where $\Psi$ is the rating of discomfort, $s_{s}$ is the static discomfort constant, $f_{t}$ is the fatigue constant, $d_{v}$ is the vibration discomfort constant, $i_{t v}$ is the interaction constant, $t$ is the time (mins) and $a$ is the frequency weighted r.s.s. acceleration. For the modelling reported here, 1.4 multipliers have been applied to horizontal axes, as per Note 4 of Section 8.2.3 of ISO 2631-1 [19] that instructs to use the multipliers if backrest vibration exists and cannot be measured.

Parameters were fitted to (1) using a sequential linear regression technique. At each time interval, the increase in discomfort was linearly modelled to provide the discomfort score for zero vibration and a multiplication factor to take into account the vibration magnitude. The relationship between each of these arrays with time was then linearly modelled. The fit for the discomfort at zero vibration at each time interval provides values for $s_{s}$ and $f_{t}$. The fit for the multiplication factors provides values for $d_{v}$ and $i_{t v}$. Other curve fitting techniques were applied including multiple regression and logarithmic fitting (to be coherent with Stevens' Power 

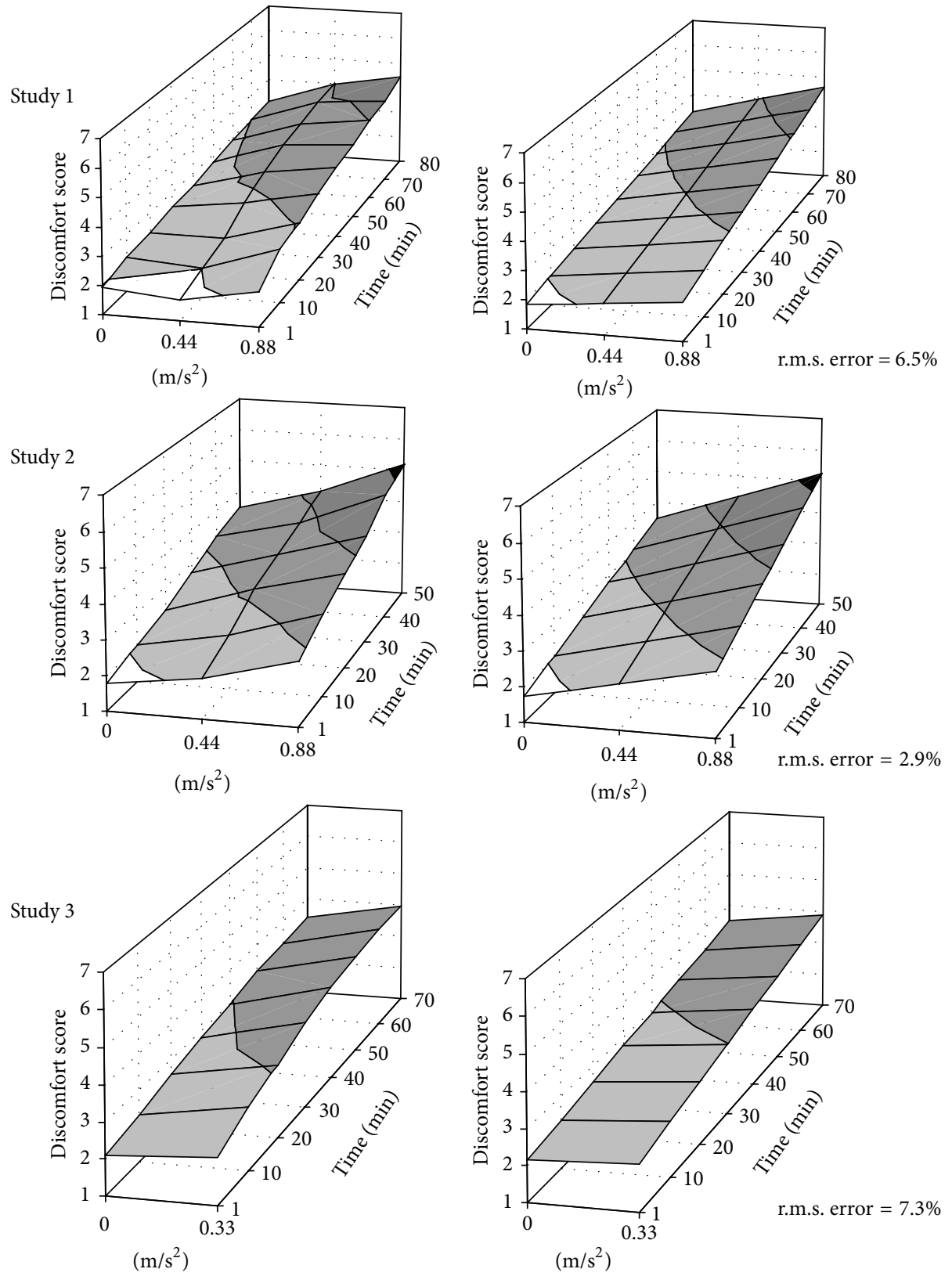

(a)

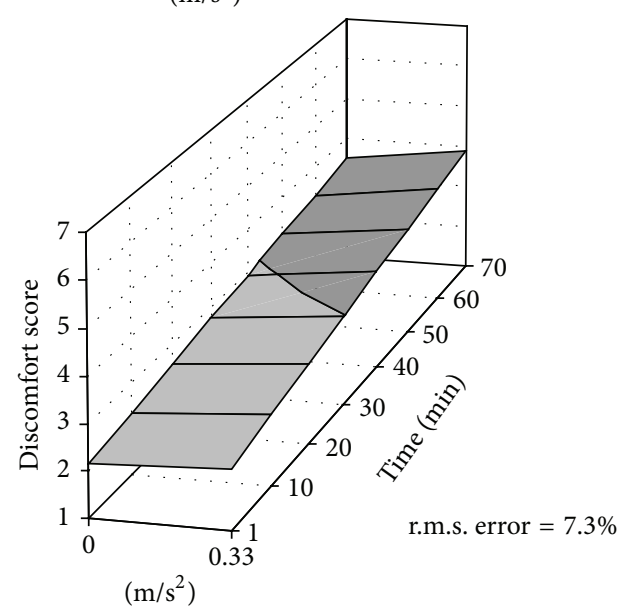

(b)

Figure 4: Mean discomfort scores for the three studies (left column) and fitted data (right column) according to the four-parameter model. Contour lines track integer discomfort scores. White: $<2$, light grey: 2-3, medium grey: 3-4, dark grey: 4-5, black: $>5$.

Law), but the fit with measured data was inferior and the technique more complex. Models were optimised to minimise the r.m.s. error, defined as the square root of the mean squared error between the predicted discomfort and measured discomfort for all magnitudes at each time interval.

Parameters fitted to (1) from the three trials provided good estimates of the overall discomfort (Figure 4). The discomfort contour maps show the nonlinearity in the development of discomfort by the curvature of the surface. This effect is evident in both the measured data and in the modelled data. Static discomfort $s_{s}$ was best for the rail seat in Study 2 and worst for the automobile seats in Study
3 (Table 2). $f_{t}$ was similar for the two automobiles $(0.018$ and $0.019 \Psi / \mathrm{min})$ but greater for the rail seat $(0.035 \Psi / \mathrm{min})$ indicating that discomfort increased more rapidly for the rail seat. $d_{v}$ was again similar for the two automobiles $(0.57$ and $\left.0.45 \Psi_{\mathrm{s}}^{2} / \mathrm{m}\right)$ and poorer for the rail seat $\left(1.31 \Psi_{\mathrm{s}}^{2} / \mathrm{m}\right)$. The interaction constant, $i_{t y}$, was similar for both Study 1 and Study 2. Three levels of vibration are required to determine $i_{t v}$ and therefore it was not possible to calculate the constant for Study 3. 0.01 was used as an estimate for $i_{t v}$ based on Study 1 and Study 2. r.m.s. errors for the fitted data were between 2.9 and $7.3 \%$. As would be expected, the best model could be fitted for the repeated measures laboratory study. 


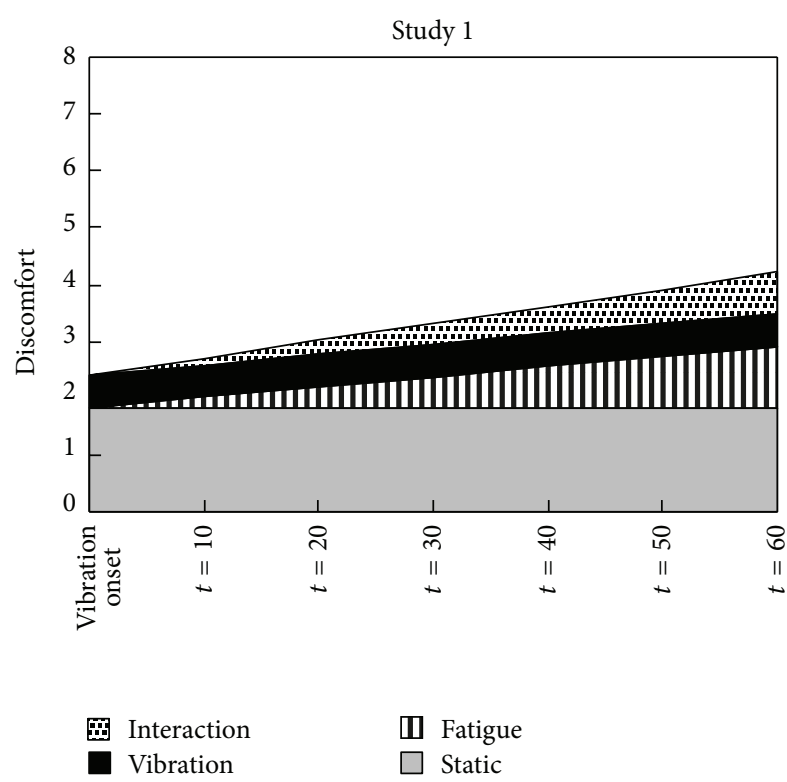

(a)

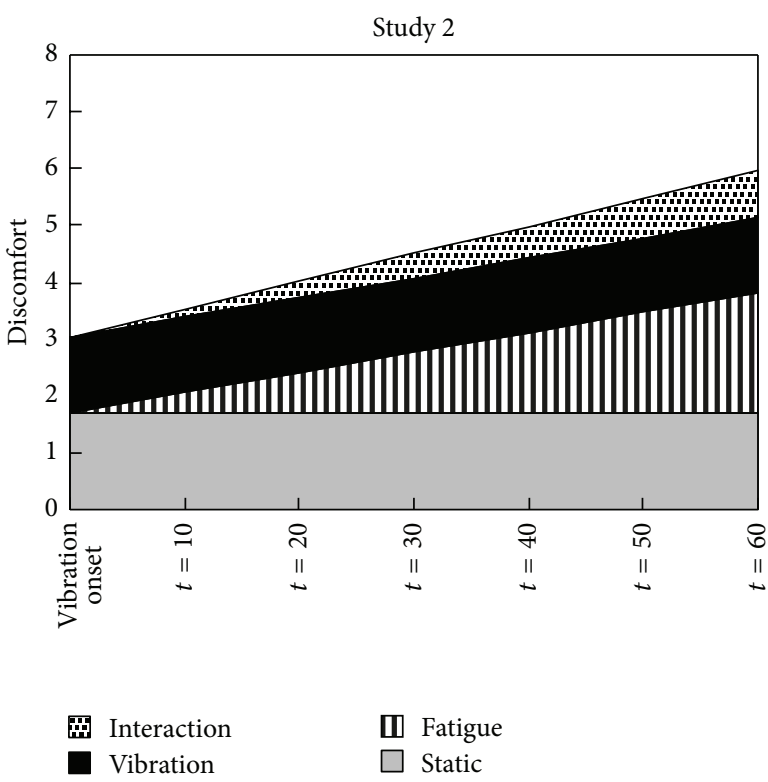

(b)

FIGURE 5: Relative contribution from each of the four variables for the Study scenarios 1 and 2, modelled to an exposure of 60 minutes at $1.0 \mathrm{~m} / \mathrm{s}^{2}$.

TABLE 2: Parameters for fitted models for the three studies.

\begin{tabular}{lccccc}
\hline & $s_{s}$ & $f_{t}$ & $d_{v}$ & $i_{t v}$ & r.m.s. error \\
\hline Study 1 & 1.84 & 0.018 & 0.57 & 0.012 & $6.5 \%$ \\
Study 2 & 1.72 & 0.035 & 1.31 & 0.014 & $2.9 \%$ \\
Study 3 & 2.16 & 0.019 & 0.45 & 0.010 & $7.3 \%$ \\
\hline
\end{tabular}

Separating each component of the model allows an investigator to study the dominant factors in the overall discomfort. Consider a scenario where the seats used in Study 1 or Study 2 were to be occupied for 60 minutes, whilst being exposed to an r.s.s. vibration magnitude of $1.0 \mathrm{~m} / \mathrm{s}^{2}$ (equivalent to V2). Results show that static factors $s_{s}$ only contribute $44 \%$ and $29 \%$ of the total discomfort at the end of the trial (Figure 5). If this seat was only tested during development using a short-term discomfort test without vibration, then the only factor to be elicited would be the value $s_{s}$, which only represents a minority of the overall contributors. If the seat design was optimised and $s_{s}$ reduced, without improvement in other areas, then the relative contribution to the overall discomfort after long-term exposures to vibration would reduce further. Temporal effects $\left(f_{t}\right.$ and $\left.i_{t v}\right)$ contribute $43 \%$ and $49 \%$ of the overall discomfort after 60 minutes; even if discomfort assessments were conducted with vibration but with only short durations, almost half of the overall contributors to discomfort would be missed. These examples illustrate the importance of considering all factors when developing seats. The seat from Study 3 is not used in this example as it was not possible to measure $i_{t v}$, but similar trends are observed if the constant is estimated.

The model still requires the user to perform some experimentation in order to determine the constants $s_{s}, f_{t}, d_{v}$, and $i_{t v}$. At this stage, it is not possible to predict these directly from the fundamentals of the seat design or the vibration waveform to which the seat is exposed. However, with experience, it might be possible to benchmark some variables such that others could form the focus of a development programme.

The studies reported in this paper show good internal agreement and are coherent with previous studies of discomfort from vibration and discomfort from long-term sitting. They were designed to use continuous vibration stimuli, and therefore results and the model cannot be directly generalised to scenarios where vibration is intermittent or varies in magnitude. Further work is required to validate and develop the model for nonstationary signal, and to include the recovery time following cessation of vibration exposure.

\section{Conclusion}

Two laboratory studies and one field study show that overall discomfort in a vehicle seat can be modelled taking into account the static discomfort in the seat, the fatigue from long-term sitting, the vibration magnitude, and an interaction between vibration and fatigue which accelerates the development of discomfort.

\section{Conflict of Interests}

The authors declare that there is no conflict of interests regarding the publication of this article.

\section{Acknowledgments}

The assistance of Gaurav Singla and Hannah Capstick in data collection is acknowledged. 


\section{References}

[1] M. J. Griffin, Handbook of Human Vibration, Academic Press, New York, NY, USA, 1990.

[2] D. E. Gyi and J. M. Porter, "Interface pressure and the prediction of car seat discomfort," Applied Ergonomics, vol. 30, no. 2, pp. 99-107, 1999.

[3] K. Ebe and M. J. Griffin, "Qualitative models of seat discomfort including static and dynamic factors," Ergonomics, vol. 43, no. 6, pp. 771-790, 2000.

[4] K. Ebe and M. J. Griffin, "Quantitative prediction of overall seat discomfort," Ergonomics, vol. 43, no. 6, pp. 791-806, 2000.

[5] G. S. Paddan, N. J. Mansfield, C. I. Arrowsmith, A. N. Rimell, S. K. King, and S. R. Holmes, "The influence of seat backrest angle on human performance during whole-body vibration," Ergonomics, vol. 55, no. 8, pp. 923-936, 2012.

[6] B. Basri and M. J. Griffin, "Equivalent comfort contours for vertical seat vibration: effect of vibration magnitude and backrest inclination," Ergonomics, vol. 55, no. 8, pp. 909-922, 2012.

[7] J. Village, C. Trask, Y. Chow, J. B. Morrison, M. Koehoorn, and $\mathrm{K}$. Teschke, "Assessing whole body vibration exposure for use in epidemiological studies of back injuries: measurements, observations and self-reports," Ergonomics, vol. 55, no. 4, pp. 415-424, 2012.

[8] J. P. Dickey, T. R. Eger, M. L. Oliver, P.-E. Boileau, L. M. Trick, and A. M. Edwards, "Multi-axis sinusoidal whole-body vibrations: part II-relationship between Vibration Total Value and discomfort varies between vibration axes," Journal of Low Frequency Noise Vibration and Active Control, vol. 26, no. 3, pp. 195-204, 2007.

[9] S. Maeda, N. J. Mansfield, and N. Shibata, "Evaluation of subjective responses to whole-body vibration exposure: effect of frequency content," International Journal of Industrial Ergonomics, vol. 38, no. 5-6, pp. 509-515, 2008.

[10] M. Kolich, N. Seal, and S. Taboun, "Automobile seat comfort prediction: statistical model versus artificial neural network," Applied Ergonomics, vol. 35, no. 3, pp. 275-284, 2004.

[11] J. M. Porter, D. E. Gyi, and H. A. Tait, "Interface pressure data and the prediction of driver discomfort in road trials," Applied Ergonomics, vol. 34, no. 3, pp. 207-214, 2003.

[12] S. Kitazaki and M. J. Griffin, "Resonance behaviour of the seated human body and effects of posture," Journal of Biomechanics, vol. 31, no. 2, pp. 143-149, 1997.

[13] N. J. Mansfield and M. J. Griffin, "Effects of posture and vibration magnitude on apparent mass and pelvis rotation during exposure to whole-body vertical vibration," Journal of Sound and Vibration, vol. 253, no. 1, pp. 93-107, 2002.

[14] N. J. Mansfield, P. Holmlund, R. Lundström, P. Lenzuni, and P. Nataletti, "Effect of vibration magnitude, vibration spectrum and muscle tension on apparent mass and cross axis transfer functions during whole-body vibration exposure," Journal of Biomechanics, vol. 39, no. 16, pp. 3062-3070, 2006.

[15] N. J. Mansfield and S. Maeda, "Effect of backrest and torso twist on the apparent mass of the seated body exposed to vertical vibration," Industrial Health, vol. 43, no. 3, pp. 413-420, 2005.

[16] A. Kjellberg and B.-O. Wikström, "Subjective reactions to whole-body vibration of short duration," Journal of Sound and Vibration, vol. 99, no. 3, pp. 415-424, 1985.

[17] C. Gallais, Effect of vibration exposure duration on discomfort [Ph.D. thesis], University of Southampton, 2008.

[18] N. J. Mansfield, Human Response to Vibration, CRC Press, London, UK, 2005.
[19] International Organization for Standardization, "Mechanical vibration and shock: evaluation of human exposure to wholebody vibration-part 1: general requirements," ISO 26311, International Organization for Standardization, Geneva, Switzerland, 1997. 

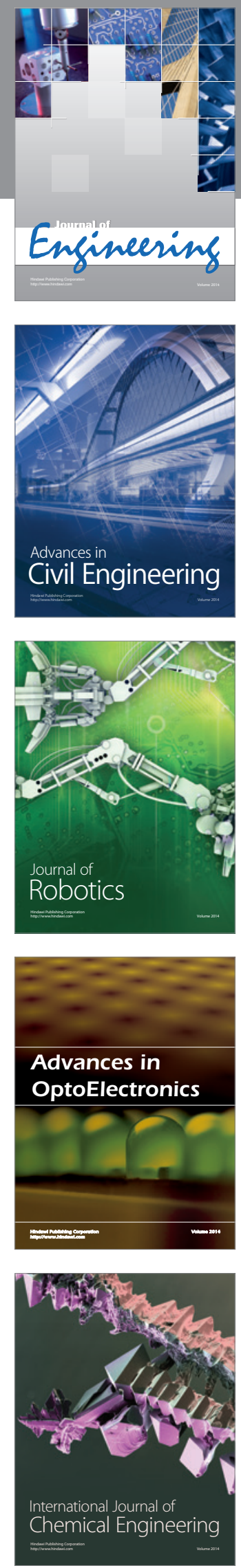

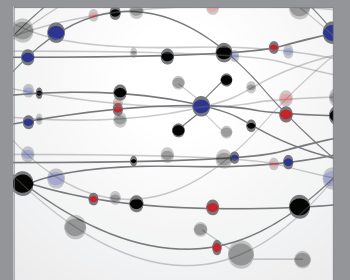

The Scientific World Journal
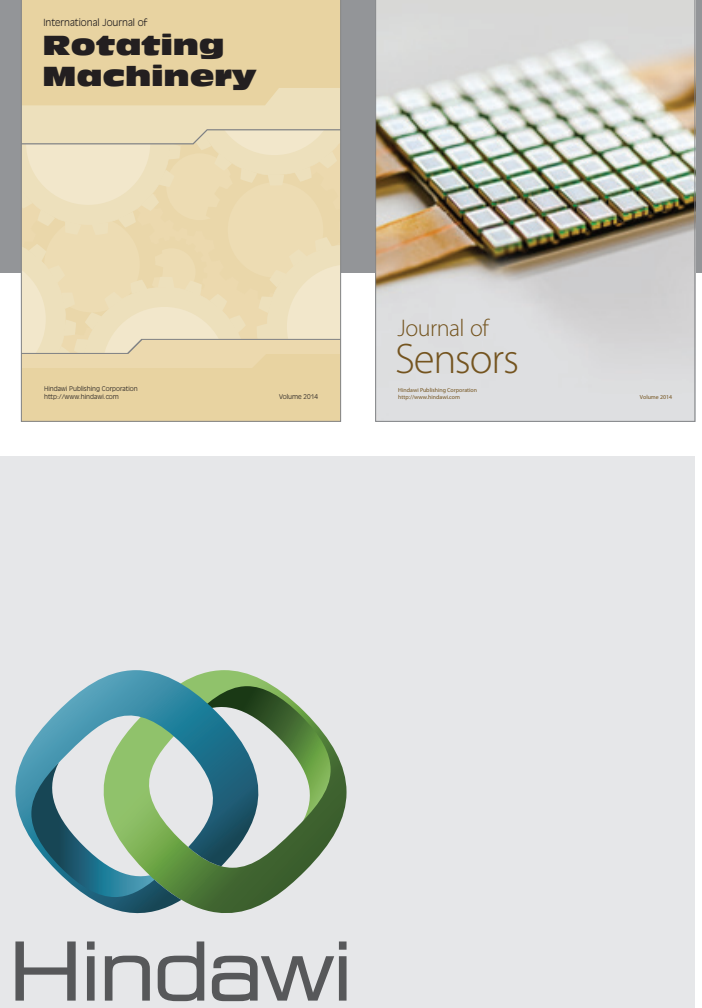

Submit your manuscripts at http://www.hindawi.com
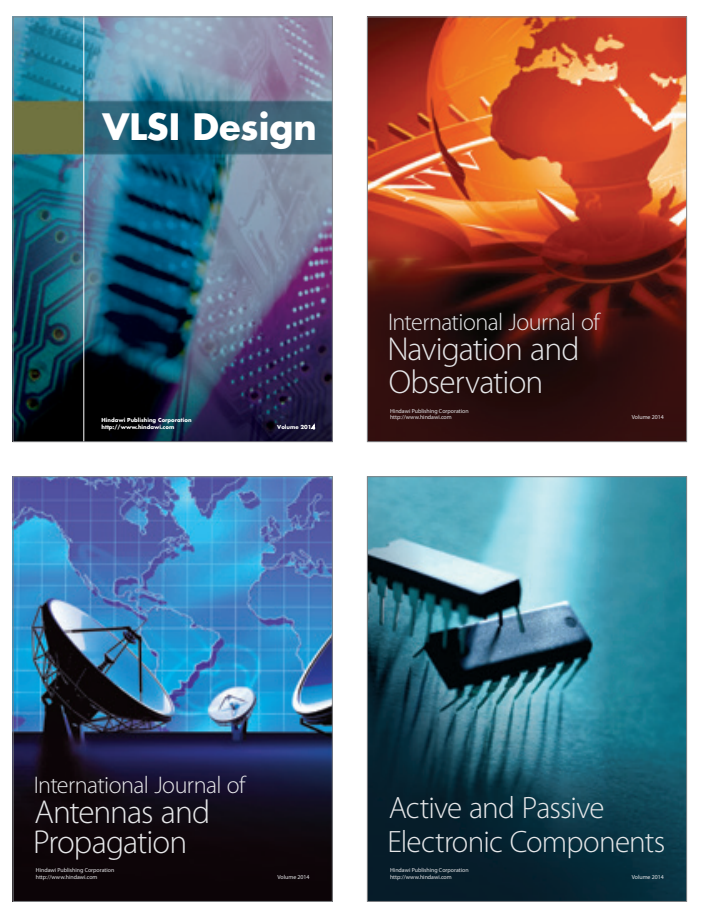
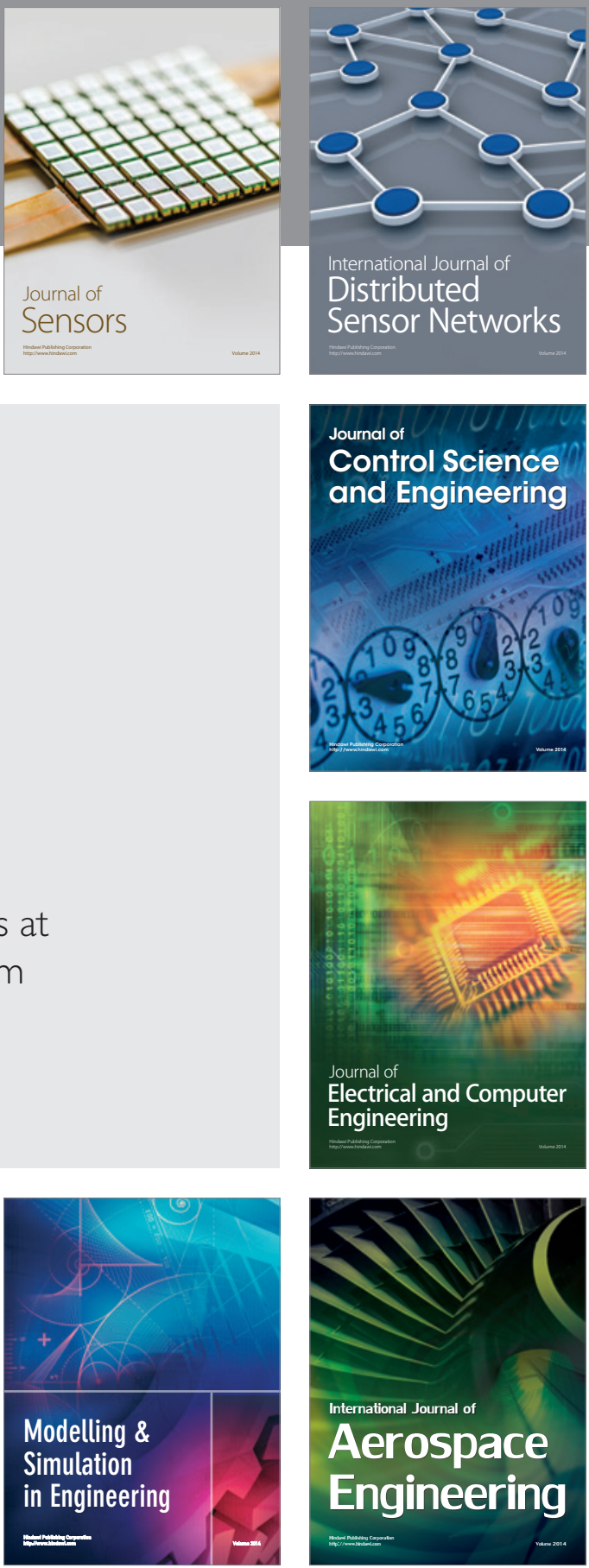

Journal of

Control Science

and Engineering
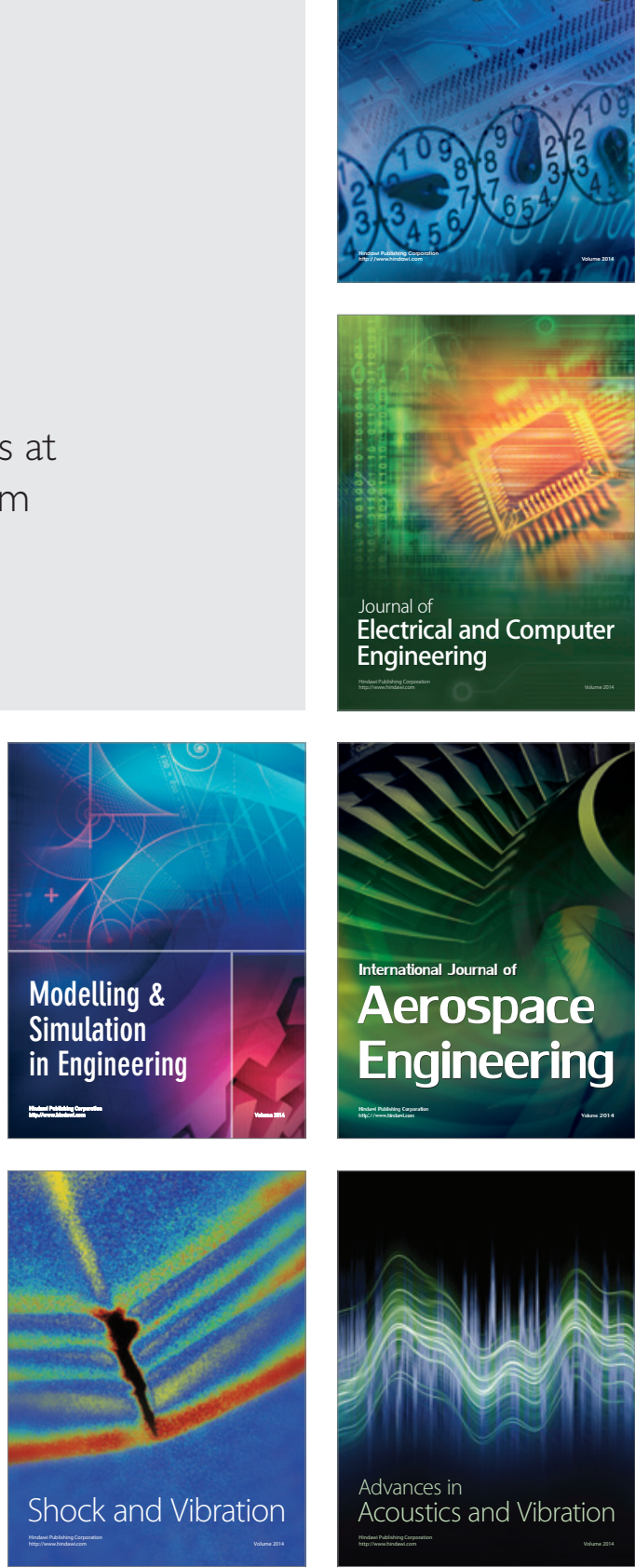